\title{
Opening up to open access
}

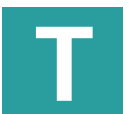

he phrase 'open access', to some, is intrinsically linked to that of 'predatory journal'. This is not surprising - the ability to charge authors fees, whether that be at acceptance or submission, brings with it plentiful opportunities for abuse by those for whom the appeal of profit outweighs that of scientific integrity. However, things have been changing over the past few years with endeavors such as Think. Check. Submit. and the Database of Open Access Journals (the DOAJ) making it easier for researchers to identify trusted journals.

BioTechniques has been publishing using some semblance of open access since before the open access movement even took hold in the life sciences, and its reputation has successfully weathered the storms that have affected other open access journals. We're also now delighted to announce that BioTechniques has been accepted for listing in the DOAJ.

The team at BioTechniques believes open access to scientific methods is key to the

\section{${ }^{6}{ }^{6}$ The team at BioTechniques believes open access to scien- tific methods is key to the success of future research...99}

success of future research, and we very much support the mission of the DOAJ to increase access to reputable, quality scholarly research across the globe. For us, this move is another step forward to ensure we best support our authors, in addition to our recent partnering with Profeza, which aims to increase accessibility and usability of the protocols that underpin our content.

Publishing open access, with its myriad licenses and mandates, can be tricky to understand for researchers hoping to maximize the visibility of their work. BioTechniques is here to help, and we hope any researchers wanting to discuss the concept will get in touch.

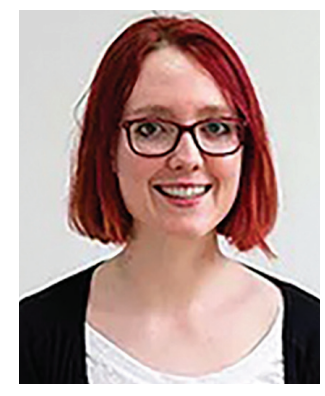

\section{Francesca Lake}

Head of Open Access Publishing, Future Science Group, Unitec House, 2 Albert Place, London, UK. f.lake@future-science.com
BioTechniques is a peer-reviewed journal dedicated to the publication of original laboratory methods, related technical tools, and methods-oriented review articles that are of broad interest to scientists engaged in basic applied life science research. Complete Instructions for Authors are available at: https://mc04.manuscriptcentral. com/fs-btn, BioTechniques' website for online manuscript submission. All manuscripts should be submitted at this site.

\section{BioTechniques Staff}

Editorial, Production \& Circulation

Chairman: James Drake

Managing Director. Phil Garner

Publisher. Cheryl Wall

Head of Open Access: Francesca Lake

Managing Editor. Joseph Martin

Digital Editor. Abigail Sawyer

Head of Production: Kathryn Berry

\section{Sales \& Business Offices}

Advertising: Cheryl Wall •cwall@biotechniques.com Subscriptions: Dominik March•d.march@future-science.com Reprints: Sam Cavana•s.cavana@future-science.com List Rental: Leela Ripton • I.ripton@future-science.com Permissions: Adriana Gonzalez•a.gonzalez@future-science.com

\section{Editorial Board}

Bill Brizzard, Indiana University Research and

\section{Technology Corp.}

Bruce Budowle, UNT Health Science Center

Piotr Chomczynski, Molecular Research Center

Rita R. Colwell, University of Maryland-College Park and Johns

Hopkins University

Joshua J. Coon, University of Wisconsin-Madison

David Cronk, Charles River Laboratories

Manel Esteller, Spanish National Cancer Centre (CNIO)

Jeffrey Felton, Western University of Health Sciences

Erica A. Golemis, Fox Chase Cancer Center

Peter M. Gresshoff, The University of Queensland

Yoshihide Hayashizaki, RIKEN

Jörg Hoheisel, German Cancer Research Center

Pui-Yan Kwok, University of California, San Francisco

Rachael L. Neve, Massachusetts Institute of Technology

Peter J. Oefner, University of Regensburg

Stephen W. Paddock, University of Wisconsin-Madison

Scott D. Patterson, Gilead Sciences, Inc.

Leonard F. Peruski, Jr., Centers for Disease Control

George Poste, Arizona State University

John Quackenbush, Harvard School of Public Health

Joshua Rappoport, Northwestern University School of Medicine

John Rossi, City of Hope

Michel Goedert, MRC

Herbert P. Schweizer, Colorado State University

Barton Slatko, New England Biolabs

Steve S. Sommer, MEDomics, LLC

Igor Stagljar, University of Toronto

Mathias Uhlén, The Royal Institute of Technology

Timothy Veenstra, SAIC-Frederick, Inc.

Kent E. Vrana, Penn State College of Medicine

Michael Weiner, AxioMx 